\title{
Genealogia das teorias marxistas de crise
}

A genealogy of marxian crisis theories

Francisco Paulo Cipolla (1)

(1) Universidade Federal do Paraná

\section{Abstract}

This article begins with a presentation of Marx's diverse contributions to the understanding of the nature of crisis under capitalism. It goes on to show that the different theories of crisis that emerged within Marxism were based on specific parts of Marx's contributions. The result is a genealogy of Marxian theories which is accompanied by the description of the debates that were engaged between the various views.

\section{Keywords}

capitalist crisis; marxian crisis theories.

JEL Codes B14.

\section{Resumo}

Este artigo procura localizar, na obra econômica de Marx, as diversas proposições acerca da natureza da crise no capitalismo realizada por aquele pensador. $O$ artigo mostra que essas proposições serviram de motivação para as diferentes teorias de crise que se originaram no interior do marxismo. Com isso foi possivel apresentar uma genealogia das teorias de crise baseada nas diferentes análises realizadas por Marx, assim como o embate realizado entre as interpretações concorrentes.

\section{Palavras-chave}

crise capitalista; teorias marxistas da crise.

Códigos JEL B14. 


\section{As motivações da teoria da crise em Marx}

São inúmeras as condições que demarcam o terreno onde germina a concepção de Marx acerca da crise no capitalismo. A condição que não poderia deixar de ser apresentada como condutora de sua apreciação sobre o tema é a sua teoria da história e o papel que teria a crise no processo de superação do capitalismo. Sendo a sua teoria da história baseada no desenvolvimento das forças produtivas e no progressivo choque desse desenvolvimento com as relações de produção dominantes, é claro que sua concepção de crise não poderia deixar de advir do desenvolvimento dessa contradição. Qual é essa contradição no capitalismo? Se a relação social fundamental na esfera da circulação é a compra e venda de força de trabalho e, na esfera da produção, a extração de mais-valia, então o desenvolvimento do capitalismo deveria ser marcado por uma tendência contínua de dominar crescentemente o trabalho no plano da produção e reduzir progressivamente a parte que representa o valor da mercadoria força de trabalho como proporção do valor total gerado durante a jornada de trabalho. Que isso devesse fazer crescer a diferença entre valor gerado pelo trabalho e poder de compra da força de trabalho era uma conclusão inevitável e de interesse imediato: o capitalismo tenderia a produzir mais do que a capacidade de consumo da sociedade. No Manifesto, deve-se entender superprodução como a produção que ultrapassa os limites impostos pelas relações de produção. É a teoria subconsumista de superprodução.

O outro condicionante do interesse de Marx sobre a teoria da crise foi o confronto entre, de um lado, Malthus e Sismondi e, de outro, os teóricos da tradição clássica, Smith e Ricardo. Nesse confronto, a vantagem analítica estava com estes últimos. De fato, em Smith, a representação do valor do produto como $v+m^{1}$ e a contrapartida nas formas de renda a que o produto dá origem impedia a possibilidade de se conceber qualquer brecha recorrente de demanda. Se a produção dá origem a formas de renda que exaurem o valor do produto, então o gasto dessas rendas deverá ser capaz de comprar o produto total. Um aumento da produção representa

1 Na verdade o valor da mercadoria para Smith é a soma de salários, lucros e renda da terra. Porém, como a renda da terra é uma dedução do lucro, Marx resume o valor do produto de Smith em $v+m$. Para um aprofundamento, veja-se o capítulo XIX do volume segundo d'O Capital cujo título é "Apresentações Anteriores do Objeto". 
um aumento das rendas e, portanto, o aumento da oferta é acompanhado de um aumento da demanda.

No entanto, é claro que aquele valor da produção é capaz de explicar apenas a reprodução das classes, mas não a reprodução do capital. O valor do produto deve incluir o valor dos materiais e a depreciação dos equipamentos que Marx representa pela letra $c$ de capital constante. De modo que o valor do produto passa a ser $c+v+m$, onde $c$ é o capital constante consumido, $v$ é o capital variável e $m$ a mais-valia.

A demanda de meios de consumo $(M C)$ dos capitalistas e trabalhadores deve ser igual à produção de $M C$. Daí que parece que o valor da produção do departamento produtor de $M C$ se resuma ao produto líquido $v+m$. O subconsumismo se baseia na ideia elementar de que $v<v+m$. Mas, para que isso faça sentido, é preciso conceber $v+m$ como sendo composto exclusivamente de $M C$, cujo montante não pode ser absorvido pelo poder de compra dos trabalhadores.

\section{Grundrisse, teorias da mais-valia}

Por ora, com base nas evidências de que o capitalismo produzia crises e com base na sua teoria da história, Marx se posicionava contrariamente à Lei de Say e, como consequência, se propunha a desenvolver a teoria das crises de Malthus e Sismondi. Mas o posicionamento de Marx face aos dois campos é de distanciamento crítico: elogiava os clássicos por terem capturado a tendência universal do capital a gerar sua própria demanda e dava crédito ao campo de Malthus e Sismondi por terem enfatizado a restrição do capital ao seu próprio desenvolvimento e termina dizendo: "A disputa sobre se a superprodução é possível e necessária no capitalismo gira ao redor de saber se o processo de realização do capital na produção implica diretamente sua realização na circulação" (Marx, 1973, p. 410). Esse é um fio condutor do qual Marx não se distanciará jamais.

\subsection{Grundisse}

Posicionando-se contrariamente a Smith, Ricardo e Say, Marx procura determinar o fundamento da crise de superprodução. Ele empreende ini- 
cialmente nos Grundrisse uma análise da predisposição do capital à crise. Uma vez que o capital procura superar todos os limites à sua valorização, a determinação dos limites que se opõem àquela valorização constituiria a sua predisposição à crise já que a tentativa de superá-los implicaria a destruição de suas condições normais de reprodução.

O aprofundamento desse veio de investigação levou Marx a buscar a base da superprodução nos limites que são impostos ao capital pela sua própria natureza. É daí que advém sua concentração no estudo do capital em geral: o estudo das tendências e limites do capital enquanto conceito independente de sua existência concreta em concorrência. Ainda não se trata do desenvolvimento da teoria da superprodução, mas apenas do estudo da predisposição a ela, predisposição que se apresenta em forma primitiva na relação do capital consigo próprio (Marx, 1973, p. 419). É nesse contexto que Marx enfatiza a ideia de que a unidade das fases de produção e circulação não é imediata: a realização do produto em dinheiro depende de condições externas à produção direta (Marx, 1973, p. 407).

Primeiramente, esse limite é apresentado como contradição entre valor e valor de uso. Enquanto o valor tem uma vocação ilimitada para a expansão, o valor de uso só pode ser consumido em quantidades limitadas pela capacidade do organismo. Aqui parece tratar-se da capacidade orgânica de consumo e, portanto, consumo determinado independentemente das relações de produção. Quando, porém, apresenta essa limitação no quantum de trabalho necessário o valor de uso como limite se torna supérfluo, pois o limite já está quantitativamente determinado pelo montante de salário. Até aqui Marx permanece dentro dos limites da visão de superprodução de subconsumo, isto é, superprodução inerente à produção de valor além do salário.

Assim, as condições de ruptura dessa unidade entre produção e circulação são apresentadas como sendo, de um lado, o caráter limitado da capacidade de consumo e, de outro, a limitação da demanda pelo poder de compra restrito do trabalho necessário. A argumentação oscila entre limite fisiológico do consumo no qual a tendência ilimitada de expansão do valor se choca com o caráter limitado da necessidade pelo valor de uso; e limite social da demanda fundada na sistemática mecanização e restrição dos salários pelo valor da força de trabalho. A coordenação dessas duas limitações aparentemente disparatadas é realizada pelo capital com o aumento da produtividade e o barateamento dos produtos. A demanda de consumo 
pode ser alargada pelos preços mais baixos, porém, somente dentro dos limites da capacidade fisiológica de consumo.

Essa é uma reafirmação do subconsumismo, mas, enquanto método, é preciso ressaltar a sua importância. Afinal, reencontraremos a tentativa do capital de saltar barreiras à sua própria reprodução normal na análise das crises cíclicas efetuada na seção cinco do terceiro volume d'O Capital. Ali, Marx parece sugerir, em conexão com a análise apresentada anteriormente nos esquemas de reprodução, que na fase de excitação do ciclo econômico, a tentativa do capital em agregado de saltar a barreira da formação de fundos de acumulação leva a um desequilíbrio entre os capitais que mobilizam dinheiro para transformação em capital produtivo $(D-M p)$ e o volume de capital produtivo disponível $(P \ldots . M p)$. Esse desequilíbrio abre a fase especulativa na qual prolifera o pseudocircuito $D-D^{\prime}$, através do qual a valorização do capital procura saltar a própria barreira da produção. Mas isso será visto mais adiante. ${ }^{2}$

Com relação às posições de Malthus e Sismondi, Marx deixa logo claro que é superficial deduzir a necessidade de superprodução do fato de que o trabalhador não pode comprar seu produto de volta (Marx, 1973, p. 424). E aqui se inicia a exploração de Marx sobre os esquemas de reprodução cuja apresentação rudimentar é realizada nos Grundrisse.

Marx apresenta pela primeira vez um esquema de reprodução com base em quatro capitais, produzindo, respectivamente, matérias-primas, maquinário, meios de consumo para os trabalhadores e meios de consumo para os capitalistas. Nesse caso, conclui ele: se os capitalistas que produzem meios de consumo para os trabalhadores o fazem em excesso em relação ao poder de compra dos trabalhadores não é porque o poder de compra dos trabalhadores é pequeno, mas porque a produção é excessiva em relação à correta proporção entre consumo e valorização. Neste caso já não se trata de subconsumo, mas de superprodução, tout court. ${ }^{3}$

2 Marx já havia acenado nos Grudrisse que o sistema de crédito se baseia na necessidade de expandir e saltar a barreira da circulação. Ao fazê-lo, o capital cria uma relativa independência da produção em relação à circulação. Daí o over-trading e over-speculation. Mas Marx não avança nesse assunto que reaparecerá no capítulo sobre o capital comercial no volume terceiro d'O Capital.

3 Nos mesmos Grundrisse, Marx apresenta uma teoria da crise baseada na diminuição da taxa de lucro dizendo que ultrapassado certo limite o desenvolvimento da produtividade se transforma numa barreira que ocasiona uma crise, mas ele não especifica qual é esse limite (Marx, 1973, p. 750). 


\subsection{Teorias da mais-valia}

Nas Teorias da Mais-valia, Marx inicia com a análise da metamorfose da mercadoria e a possibilidade de crise que ela contém quando o motivo de transformar a mercadoria em dinheiro for maior do que o motivo de transformar dinheiro novamente em mercadoria (Marx, 1968, p. 505). A contradição inerente à circulação de mercadorias reaparece aumentada no capital, já que com o capital a circulação de mercadorias se desenvolve. A fase $M-D$ de um capital é fase $D-M$ de outro: a divisão do trabalho requer essa interconexão, mas essa interconexão é acidental. Portanto, a definição do conteúdo da crise fica mais completa. Com a função de meio de pagamento do dinheiro, o capital cria uma base mais concreta para transformar as condições de crise em realidade, já que qualquer interrupção das vendas em um ponto se irradia rapidamente pela cadeia de pagamentos postergados pela circulação de notas promissórias como meio de circulação.

Marx ainda repete a visão subconsumista: a base da superprodução moderna está na contradição entre a tendência ao desenvolvimento ilimitado das forças produtivas e a limitação do consumo dos trabalhadores ao estritamente necessário, fato que parece um recuo em relação à evolução realizada anteriormente (Marx, 1968, p. 528). A concepção de superprodução como superprodução em alguns ramos importantes e sua irradiação ao resto da economia também está atrelada à visão subconsumista na medida em que se trata, segundo Marx, de ramos de meios de consumo. Mas, uma vez realizada a superprodução num ramo chave, ela se irradia, potencializada ao nível das relações de crédito pela função do dinheiro como meio de pagamento (Marx, 1968, p. 529).

Como exemplo ilustrativo, tenha-se em mente o caso apresentado por Marx no qual o excesso de produção de pano de algodão leva à diminuição do emprego no ramo de tecelagem, fato que afeta o ramo de fiação e consequentemente a produção de algodão. Portanto, a normal reprodução em todos esses ramos é impedida pela anormal reprodução no ramo da tecelagem. Mesmo não tendo tido superprodução, esses ramos agora apresentam excesso de produção devido à queda da demanda (p. 522-523). Por isso Marx denomina essa superprodução de superprodução relativa. A superprodução absoluta em alguns ramos líderes leva a uma mais ou menos generalizada superprodução relativa nos outros ramos da economia. 
A produção no limite das forças produtivas, isto é, a exploração do máximo de trabalho sem consideração pelos limites do mercado em contraposição à capacidade limitada de consumo da massa dos produtores ( $\mathrm{p}$. 535), continua sendo o pano de fundo da teoria da crise. Na Teoria da Mais- valia a magnitude da necessidade social é limitada pela restrição do consumo dos trabalhadores e, portanto, uma produção além da capacidade de compra dos trabalhadores leva a uma superprodução absoluta no ramo. É importante notar que a noção de superprodução se afirma exclusivamente com relação aos meios de consumo em excesso. De qualquer modo, a linha divisória entre subconsumo e superprodução começa a ficar mais nítida já que a produção além das necessidades de consumo não é devido à diferença $v<v+m$, mas devido à diferença entre o valor total produzido num ramo chave de meios de consumo $\left(c_{j}+v_{j}+m_{j}\right)$ e a demanda agregada dos trabalhadores por esse produto, $v_{j}$, ou seja, $\left(c_{j}+v_{j}+m_{j}\right)>v_{j}$, em que $j$ é o setor que apresenta superprodução absoluta e $v_{j}$ é a parcela do salários destinada à compra da mercadoria $j$.

Ao longo d'O Capital, Marx não deixou de sublinhar todos os momentos teóricos nos quais se apresentava a possibilidade de ruptura do processo normal de reprodução. Como a trajetória da exposição, caminha dos conceitos mais abstratos aos mais concretos, as possibilidades de ruptura que se apresentam ao longo da exposição estão quase sempre circunscritas a níveis abstratos de análise ${ }^{4}$ circunstância que deu origem à equivocada divisão da teoria de Marx entre teoria da possibilidade de crise e teoria da necessidade de crise, dicotomia que não parece ser compatível com o método de análise de Marx. A expressão possibilidade de crise deveria ser substituída por condições abstratas de crise.

As condições abstratas da crise podem ser ilustradas com o auxílio do circuito do capital industrial adicionado do capital portador de juros $(D-D)$ que supre os empréstimos e do capital comercial $\left(D_{v}-M-D^{\prime}\right)$ que realiza, como capital independente, a última fase do circuito e onde $D_{v}$ é o valor de venda do industrial para o comerciante:

$$
D-D-M \ldots . P \ldots M^{\prime}-D_{v}-M-D^{\prime}
$$

4 Sweezy leva essa mesma consideração ao extremo de dizer que Marx não terminou o tratamento da concorrência e do crédito e que todo o trabalho d'O Capital permaneceu a um nível de abstração inadequado para o tratamento teórico da crise (Sweezy, 1973, p. 164). Teria sido insuficiente o tratamento de Marx às questões do crédito apresentadas no volume terceiro? 
Visto dessa forma, as rupturas no processo normal de reprodução podem ter origens diversas: elas podem se originar no capital monetário cuja esfera imediata são os bancos, as bolsas de valores e a finanças, isto é, a esfera do capital portador de juros (Marx, 1985a, p. 116) com possíveis efeitos sobre a indústria; podem se originar no capital comercial, com a interrupção do escoamento da produção e seus possíveis efeitos sobre a indústria (Marx, 1988, p. 218); ou pode originar-se como uma crise industrial propriamente dita, pela qual Marx quer dizer estancamento da produção, falências, desemprego, e assim por diante.

A análise das crises cíclicas não poderia ter sido apresentada ao longo da exposição d'O Capital porque ela requereria o estudo da concorrência e do crédito, níveis mais concretos da análise que só poderiam ser apresentados após a reunião dos elementos explicativos intermediários. Isso significa que todas as observações anteriores à análise do crédito e da concorrência tinham um caráter ainda muito abstrato para serem consideradas teorias da crise.

\section{Leque de teorias n'O Capital}

N'O Capital, Marx apresenta várias "teorias" de crise. Sem levar em conta a crise monetária apresentada logo no capítulo 3 , mas que não é senão uma fase de toda crise, suas "teorias" poderiam ser compiladas assim:

\subsection{Sobreacumulação relativamente à população explorável}

Esta teoria é explicitamente apresentada no capítulo XV do terceiro volume d'O Capital sobre o "Desdobramento das Contradições Internas da Lei".

Se, portanto, o capital tivesse crescido proporcionalmente à população trabathadora, de forma tal que nem o tempo absoluto de trabalho fornecido por essa população nem o tempo relativo de mais-trabalho pudessem ser ampliados... se, portanto, o capital acrescido só produzisse tanta massa de valor ou até menos do que antes de seu crescimentos, então ocorreria uma superprodução absoluta do capital; isto é, o capital acrescido $C+\Delta C$ não produziria lucro maior. (Marx, 1988, p. 181).

5 Aqui há um erro de tradução ou typo já que segue dizendo "nem mesmo menos lucro" enquanto na edição da International Publishers se lê "or even less" ao que deveria seguir em português "e mesmo até menor". 
A necessária eliminação de $\Delta \mathrm{C}$ resultaria em vendas a menores preços; desvalorização de títulos sobre a mais-valia; interrupção da função do dinheiro como meio de pagamento; colapso do sistema de crédito e, finalmente, queda dos salários e desvalorização do capital, com o que se lançariam as bases para a realização de um novo ciclo econômico (Marx, 1988, p. 182-183).

No capítulo XXIII sobre a Lei Geral da Acumulação Capitalista, o item que trata do aumento da demanda de força de trabalho que acompanha a acumulação quando a composição do capital se mantém constante (Marx, 1985b, p. 187) não pode ser incluído como evidência da mesma teoria. A razão disso é que Marx não apresenta o aumento da demanda de trabalho e dos salários como causa de crise, mas apenas como a variável dependente da acumulação que reage sobre o ritmo de acumulação, uma vez que esta faz aumentar os salários. Essa seção retrata um regime cíclico de acumulação autolimitado pelo seu efeito sobre os salários. Itoh se utiliza dessa análise argumentando que os períodos de rápido crescimento coincidem com baixos ritmos de aumento da composição do capital, fato que corroboraria a utilização da análise cíclica com base na composição constante do capital efetuada por Marx naquela seção como componente de sua teoria de crise de sobreacumulação. Quanto à afirmação de que "as crises são gestadas precisamente nos períodos nos quais os salários sobem e os trabalhadores absorvem uma parcela maior do produto anual destinado ao consumo" (Marx, 1985c, p. 304), essa afirmação não apresenta nenhuma relação de causa e efeito com a crise, apenas de contemporaneidade da fase de expansão com o aumento dos salários, fato, aliás, que deveria ser considerado trivial dado o maior volume de emprego relativamente à força de trabalho disponível.

\subsection{Esquemas de reprodução: as condições de balanço da reprodu- ção são igualmente condições de crise}

Ao analisar a formação de fundos de acumulação, Marx se defronta com o problema de que o balanço da reprodução ampliada depende de que o dinheiro retirado de circulação para formar esses fundos seja compensado pela introdução na circulação de fundos acumulados anteriormente. Em relação a esse problema, ele diz que as condições para o 
Curso normal da reprodução, seja ela em escala simples, seja em escala ampliada... se convertem em outras tantas condições do curso anormal, em possibilidades de crises, uma vez que o próprio equilíbrio - em face da configuração naturalmente desenvolvida dessa produção - é uma coincidência. (Marx, 1985c, p. 361).

A seção 2 do capítulo sobre a "Reprodução Simples", seção intitulada "Reposição do Capital Fixo em Natura", lida com o problema da coordenação entre uma seção do departamento II que acumula o fundo de depreciação e a outra que repõe o capital fixo depreciado. De leitura fatigante, esse trecho apresenta a seguinte conclusão:

Esse exemplo do capital fixo - com escala constante de reprodução - é contundente. Desproporção na produção de capital fixo e circulante é um dos motivos prediletos dos economistas para explicar as crises. É algo novo para eles que tal desproporção possa e tenha de surgir com a mera conservação do capital fixo ou que possa e tenha de surgir pressupondo-se uma produção normal ideal, com reprodução simples do capital social já em funcionamento. (Marx, 1985c, p. 342).

Como se sabe, a condição de balanço da reprodução simples é $c_{\mathrm{II}}=v_{\mathrm{I}}+m_{\mathrm{I}}$. Suponhamos que $c_{\text {II }}=2000$ se divida em 1800 de capital constante circulante e 200 de depreciação do capital fixo retirado da circulação e conservado na forma de capital dinheiro potencial até que seja necessário repor o capital fixo in natura. No entanto, se alguns capitalistas retiram de circulação o valor de 200 correspondente à depreciação, outros deverão utilizar seus fundos previamente acumulados no montante de 200. Somente assim a condição da reprodução simples pode se viabilizar. Se por acaso venhamos a ter uma retirada de 300 sem que essa retirada seja compensada por uma injeção de gastos do mesmo valor - supondo que a reposição in natura se mantenha em 200 - então teremos falta de capital fixo e excesso de capital circulante.

\subsection{A capacidade restrita de consumo dos trabalhadores}

A ideia de que a capacidade restrita de consumo dos trabalhadores é a causa última de todas as crises aparece no contexto de sua análise mais concreta sobre as crises, fato que requer mais reflexão da nossa parte ou talvez signifique que as descobertas realizadas com a pesquisa sobre a circulação do capital no volume segundo não foram transcritas para o nível do volume terceiro, terminado anteriormente.

Ao analisar o impulso que o crédito fornece à fase de expansão da produção, Marx diz que 
O máximo crédito é aqui igual à mais plena ocupação do capital industrial, isto é, à ativação extrema de sua força de reprodução, sem preocupação pelos limites do consumo. Esses limites do consumo são ampliados pela própria ativação do processo de reprodução; esta aumenta, por um lado, o consumo de rendimento por trabalhadores e capitalistas e, por outro, é idêntica com a ativação do consumo produtivo. (Marx, 1986, p. 23).

Após dizer que a capacidade de consumo dos trabalhadores é limitada pelos salários e pelo fato de que somente são empregados se puderem produzir lucro para os capitalistas ele lança a frase célebre:

A razão última de todas as crises reais é sempre a pobreza e a restrição ao consumo das massas em face do impulso da produção capitalista a desenvolver as forças produtivas como se apenas a capacidade absoluta de consumo da sociedade constituísse seu limite (Marx, 1986, p. 24).

É interessante notar que no livro sobre A Circulação do Capital, mais precisamente no capítulo XX sobre A Reprodução Simples, Marx ataca a ideia de que a crise pudesse ser causada pelo fato dos trabalhadores receberem uma fração muito pequena do valor por eles produzido dizendo: "as crises são sempre preparadas justamente por um período em que os salários sobem de modo geral e a classe trabalhadora obtém realiter participação maior na parte do produto anual destinada ao consumo". E criticando aqueles que pensavam que um aumento dos salários poderia ser a solução, termina dizendo: "Tal período deveria... ao contrário, afastar a crise" (Marx, 1985c, p. 304).

\subsection{Caráter cíclico das crises no qual ele realça a concorrência e o crédito, a superprodução, a especulação e a crise}

Esse conceito veio da teoria da crise que se apresenta na seção V, principalmente na segunda parte do livro terceiro d'O Capital. Os três capítulos sobre Capital Monetário e capital Real podem ser vistos como uma reunião dos elementos anteriormente desenvolvidos ao longo de toda a obra. Esta concepção foi a que menos desenvolvimento suscitou, exceto quando no interior de outra causalidade como, por exemplo, na teoria de Itoh que partindo da sobreacumulação causada pelo aumento dos salários, apresenta os principais desdobramentos da ruptura do processo normal de reprodução, apoiando-se na análise apresentada naquela parte do volume terceiro d'O Capital. 


\section{Matrizes e genealogia das teorias marxistas de crise}

Quadro 1, abaixo, resume as diferentes sugestões teóricas apresentadas por Marx ao longo d'O Capital.

Quadro 1 Classificação das teorias de crise $^{6}$

\begin{tabular}{l|l}
\hline Teoria & Fundamento \\
\hline A. Teoria subconsumista da crise & Escritos econômicos de Marx antes d'O Capital \\
\hline $\begin{array}{l}\text { B. Teoria da desproporcionalidade } \\
\text { C. Queda da taxa de lucro causada pelo } \\
\text { aumento dos salários }\end{array}$ & $\begin{array}{l}\text { Esquemas de reprodução do segundo volume } \\
\text { C'O Capital }\end{array}$ \\
\hline $\begin{array}{l}\text { D. Queda da taxa de lucro causada pelo } \\
\text { aumento da composa Luxemão orgânica do capital }\end{array}$ & Crítica de Grossmann a Bauer \\
\hline
\end{tabular}

Figura 1 Genealogia das teorias marxistas de crise ${ }^{7}$

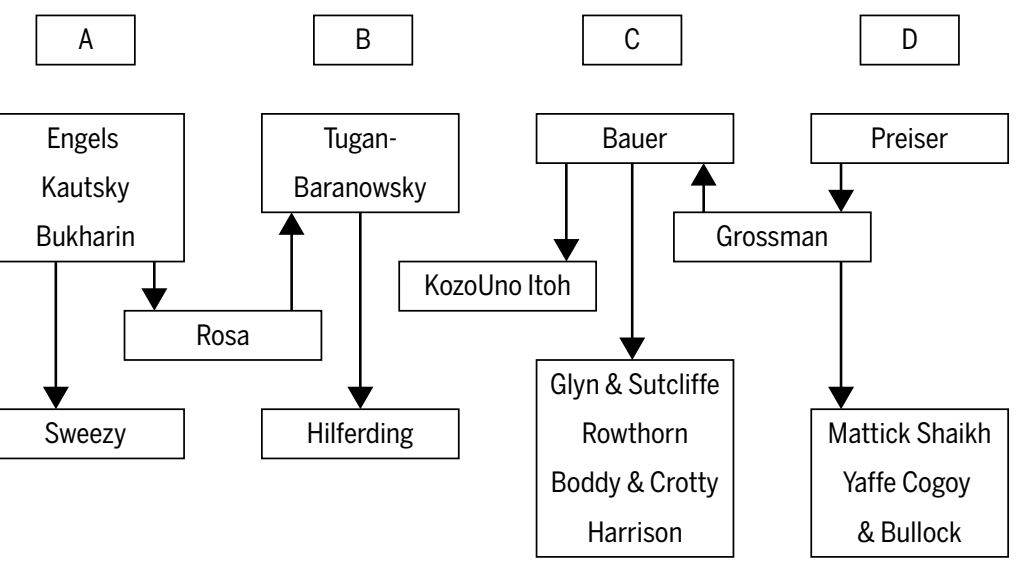

As linhagens teóricas a partir das contribuições teóricas de Marx e seus ulteriores desdobramentos históricos podem ser apresentadas no organogra-

6 Itoh (1980) classifica as duas primeiras como teorias de excesso de mercadorias e as duas últimas como teorias de excesso de capital.

7 Como se vê nesse sketch dos grandes autores marxistas, não constam figuras importantes como Mandel e Dobb, por exemplo. A sua inclusão dependeria de se saber sob quais contribuições eles se apoiam, já que suas teorias combinam mais de uma possível causa para as crises econômicas (Itoh 1980, p. 129). Isso deverá ser realizado em breve. No caso de Dobb, é possível classificá-lo junto com Uno e Itoh já que ele partilha da concepção de crise de sobreacumulação causada pelo aumento dos salários. 
ma genealógico da Figura 1, onde as setas para baixo indicam descendência enquanto as setas para cima representam direção da crítica. As letras A, B, C, D, no topo das linhagens, correspondem à classificação do Quadro 1. A história das teorias de crise pode assim ser vista como uma trajetória de mutações causada pelo embate entre concepções antagônicas.

\section{Hegemonia subconsumista e a desproporcionalidade}

As teorias de crise cíclica do capitalismo quase invariavelmente deram origem a mutações teóricas reformistas. Esse foi o caso de Kautsky, Tugan-Baranowsky e Hilferding. As teorias de colapso se desenvolveram por oposição às teorias que tinham implícitas nelas a possibilidade de contínua regeneração do capitalismo. Essa foi a resposta de Luxemburgo a Tugan-Baranowsky e exatamente o mesmo pode-se dizer da resposta de Grossmann a Bauer. É preciso esclarecer, para evitarmos equívocos, que a teoria do colapso não implica a inexistência de crises cíclicas, mas apenas que essas crises cíclicas são os espasmos da tendência ao colapso contido pelo desenvolvimento de contra-tendências, como nos casos de Preiser e Grossmann, por exemplo. ${ }^{8}$

As análises de Marx sobre a contradição entre forças produtivas e relações de produção no capitalismo e sua necessidade de expansão mundial por meio da exploração de mercados externos são recorrentes e aparecem nos livros anteriores ao $O$ Capital. A combinação de subconsumo e expansão colonial veio a se constituir numa espécie de dogma da social democracia alemã.

No contexto da luta política contra Berstein, Kautsky, por exemplo, faz uso da visão subconsumista apresentada por Marx. O subconsumismo para ele nada mais é do que a tendência contínua do capital de produzir mais do que os trabalhadores podem consumir. A necessidade de expansão de mercados externos não capitalistas apenas reproduz o mesmo problema numa escala ainda mais ampla. ${ }^{9}$

8 Preiser, inacessível sem o conhecimento do alemão, é apresentado por Itoh como o precursor de Grossmann. Segundo Itoh (1980, p. 126-127), Preiser deriva a necessidade de crises periódicas a partir da tendência à crise absoluta que deveria ocorrer quando, devido à queda da taxa de lucro, os capitalistas abandonariam a produção. Essas crises periódicas serviriam para sanar temporariamente o sistema por meio da desvalorização do capital. De fato, a análise se assemelha muito às proposições de Grossmann.

9 Howard; King, 1989, v.I, p. 82-83. 
A razão subconsumista pode ser apresentada assim: utilizando a notação de Giussani (1983), definamos $k_{c}$ como a proporção da mais-valia utilizada para expandir o capital constante; $k_{v}$ como a proporção da mais-valia utilizada para expandir o capital variável e $1-\left(k_{c}+k_{v}\right)$ como a proporção da mais-valia utilizada para o consumo dos capitalistas. A proporção da mais-valia consumida pelos capitalistas tende a decrescer. Isso implica que a proporção $k_{c}+k_{v}$ tem que crescer. No entanto, $k_{c} / k_{v}$ tende a crescer ao longo do tempo o que significa que a proporção da mais-valia capitalizada que se transforma em capital variável adicional cai continuamente. É necessário, portanto, argumentam eles, que cresça continuamente a proporção da mais-valia destinada às máquinas, equipamentos, instrumentos, instalações, tudo que representa o capital constante e que aumenta a produtividade do trabalho. Mas isso, dizem eles, só aumenta a produção de meios de consumo que não pode ser absorvida pelos trabalhadores ou pelos capitalistas. Ergo, crise! Esse é o argumento padrão apresentado por Sweezy e outros. É claro que o defeito desse raciocínio, como muito bem apontou Shaikh (1978), é conceber a produção de máquinas e equipamentos como simples meio de produzir meios de consumo.

Com o segundo livro d'O Capital finalmente disponível, Lênin, Tugan, Bulgakov e Struve puderam travar a batalha decisiva ao redor do problema do desenvolvimento do capitalismo na Rússia. Lênin, servindo-se das contribuições de Bulgakov e Tugan-Baranowsky, e principalmente da analise da reprodução empreendida por Marx no segundo volume d'O Capital, procura responder à questão de como se desenvolve o mercado interno para o capitalismo russo, desenvolvimento esse que os populistas russos, nas figuras de V. P. Vorontsov e N. F. Danielson, conhecido pelo pseudônimo de Nikolai-on, reputavam impossível. Os populistas russos defendiam a necessidade da passagem direta da comunidade rural, o mir, para o socialismo. Segundo eles, o capitalismo não poderia se desenvolver na Rússia, pois, diferentemente dos países imperialistas da Europa Central, a Rússia, tendo chegado atrasadamente no cenário imperialista mundial, não poderia encontrar mercados externos para escoar o excesso de produção em relação à exígua capacidade de consumo dos trabalhadores russos. $O$ conduto de vazão clássico para o subconsumo, os mercados externos, estava bloqueado para a Rússia, segundo os populistas russos.

No contexto do debate russo, Tugan-Baranowsky teve uma importante participação. Com base nos esquemas de reprodução de Marx ele pro- 
curou argumentar que, se as proporções entre os departamentos forem obedecidas, o sistema poderia se reproduzir indefinidamente numa escala crescente sem que houvesse nenhum problema de realização já que a demanda se produziria internamente ao processo de acumulação. Porém, como a produção capitalista é anárquica, inevitavelmente sobreviriam circunstâncias nas quais as corretas proporções entre os vários departamentos não seriam realizadas e o sistema entraria em crise. A crise seria o processo de saneamento dessas desproporções entre os vários setores da economia e, portanto, a cura que permitiria a retomada da acumulação.

A crítica aos marxistas populistas russos representou um ataque mortal ao subconsumismo, mas, também, a abertura de uma vertente reformista. Kautsky, Hilferding e Tugan partilhavam da ideia de que com a centralização dos capitais seria possível evitar as desproporções entre os vários segmentos da economia por meio da crescente organização do capitalismo. ${ }^{10}$

\subsection{Hilferding}

Hilferding dá crédito a Tugan por ter direcionado a atenção do estudo das crises para a análise dos esquemas de reprodução de Marx, apesar de manter uma distância crítica em relação à sua concepção do consumo como sendo irrelevante para a reprodução (Hilferding, 1985, nota 4, p. 421).

Hilferding inicia sua análise das condições de crise com a interrupção da função do dinheiro como meio de circulação na metamorfose da mercadoria, mas circunscreve esse evento a uma área limitada de impacto. Quando passa a considerar a condição de crise a partir da interrupção da função do dinheiro como meio de pagamento, as coisas mudam de figura. As notas promissórias a que a função do dinheiro como meio de pagamento dá origem circulam como dinheiro, encadeando a quitação da dívida ao longo de toda uma série de compras e vendas, de tal maneira que a incapacidade de vender num ponto se irradia para toda a cadeia de pagamentos a serem quitados. Em seguida, apresenta a terceira condição de crise que é a separação entre produção e consumo (p.241) dizendo que as crises se tornam

10 Shaikh diz: "Both Tugan-Baranowsky and Hiferding were later to argue that since it was the anarchy of capitalism which led to crises, planning would eliminate crises. 'Organized capitalism' in Hilferding's words, was the solution, and the parliamentary path to State control was the means." (Shaikh 1978, p.228). 
uma possibilidade real somente quando a coordenação entre consumo e produção é eliminada.

Hilferding (1985) divide a sua análise sobre as crises em duas partes que correspondem aos capítulos 16 e 17. Na primeira abordagem, ele trata de estabelecer as condições sob as quais uma crise pode vir a ocorrer. Essas condições, como veremos a seguir, são as possíveis desproporcionalidades às quais está sujeito um sistema cujo balanço entre as suas várias partes é executado pelas forças dispersas do mercado. Na segunda abordagem, ele trata de precisar como essas desproporções são produzidas sistematicamente pelo ciclo econômico.

No capítulo 16, ele se ocupa das questões relativas às condições de balanço da reprodução. Repetindo de modo muito didático a análise de Marx, Hilferding mostra que a reprodução ampliada depende de duas condições. A primeira se refere à necessidade de equilíbrio entre o volume de capital dinheiro referente à depreciação que é retirado da circulação e o volume de capital dinheiro que retorna à circulação para repor o capital fixo já completamente depreciado. Essa condição que forma a base da reprodução ampliada é analisada por Marx no contexto da reprodução simples e o mesmo é feito por Hilferding. ${ }^{11}$ A segunda condição é que aos fluxos de fundos de acumulação retirados da circulação correspondam fluxos de transformação de capital dinheiro anteriormente acumulado em capital produtivo adicional. Aqui temos a conhecida distinção entre capitalistas que vendem mas não gastam a parte da mais-valia a ser acumulada, isto é, os capitalistas denominados de tipo A; e os capitalistas que compram à partir de seus tesouros acumulados anteriormente, os capitalistas de tipo B.

Hilferding utiliza assim os esquemas de Marx para mostrar que as condições de balanço da reprodução, seja ela simples ou ampliada, podem se transformar em causa de crises se fossem violadas (p.256). Contrariando a tese subconsumista, ele diz que uma crise pode resultar até de uma expansão muito rápida do consumo da sociedade.

No capítulo 17, ele procura mostrar que as desproporções são causadas pelo distúrbio da relação de preços entre indústrias de alta e de baixa $c / v$. As primeiras têm um maior aumento de preços durante a primeira fase

11 Ele também se refere às possíveis desproporções entre capital fixo e capital circulante que resultam de divergências entre formação de fundo de depreciação e reposição de capital fixo depreciado. 
da expansão, pois se adaptam mais lentamente ao aumento da demanda. Por outro lado, as indústrias de mais baixa composição do capital respondem mais rapidamente ao aumento de preços. Essa distorção de preços cria uma tendência ao investimento excessivo nas indústrias de mais alta tecnologia, cujo produto não poderá ser comprado na sua totalidade pelas indústrias que cresceram mais rapidamente. Haveria então uma superprodução de meios de produção.

\subsection{Luxemburgo}

Para Rosa Luxemburgo, o socialismo não seria objetivamente necessário se não se pudesse provar que o capitalismo caminha para a sua ruína absoluta, que nos termos de sua teoria seria o colapso da reprodução por exaustão dos mercados não capitalistas.

O livro de Rosa, A Acumulação de Capital, visa mostrar que o capitalismo não pode existir sem mercados não capitalistas. $O$ colapso do capitalismo deveria advir da exaustão dessas reservas de mercado à medida que o capitalismo lança suas raízes na periferia não capitalista. Mas para isso ela precisou atacar o coração da teoria da realização de Marx: os esquemas de reprodução. Como haviam sido os esquemas de reprodução a arma teórica principal utilizada contra os narodnikis russos, Rosa não hesita em atacar diretamente os esquemas de reprodução como sendo uma representação incongruente do capitalismo.

Rosa argumenta que os esquemas de reprodução são apropriados para representar o crescimento de uma sociedade planejada do tipo socialista (Luxemburgo, 1976, p. 119), pois eles descrevem um processo regido pelas necessidades de consumo social. Eles são, no entanto, incapazes de representar a acumulação capitalista, pois não revelam a origem da demanda pelo produto excedente, isto é, não fornecem a motivação subjacente à expansão contínua da produção. Para explicar a acumulação capitalista, argumenta ela, é preciso uma fonte de demanda prévia que justifique a expansão da capacidade produtiva.

O produto excedente requer um escoamento exterior ao capitalismo, mas não só. Uma vez transformado em dinheiro, a transformação dessa mais-valia em capital adicional requer a perspectiva de mercados ainda maiores (Luxemburgo, 1976, p. 124). Ela não vê a possibilidade de que ao 
pagarem os trabalhadores adicionais no departamento I, estes comprem meios de consumo $(M C)$ no departamento II e que os capitalistas do departamento II comprem meios de produção $(M P)$ adicionais no departamento I.

Para Rosa, Marx se ocupa da questão errada. O problema segundo ela não é a origem do dinheiro, mas a origem da demanda. No caso da reprodução simples, ela aceita a solução de Marx: os capitalistas têm o dinheiro para a compra dos seus meios de consumo nos quais se materializam toda a mais-valia da sociedade. Mas ela não aceita a solução fornecida por Marx para a reprodução ampliada.

Mas Marx se ocupa do problema da origem do dinheiro porque para ele o problema da origem da demanda já não existe. O problema da demanda está resolvido pela existência de uma condição de balanço da reprodução. Desde que essa condição de balanço se realize, a acumulação dos capitais cria demanda recíproca entre eles. Subsiste o problema da circulação da massa crescente de valor das mercadorias. $O$ problema de fato se refere à realização de uma massa acrescida de capital na forma de capital mercadoria, a qual na circulação só pode funcionar como mercadoria a ser vendida. Para Marx, o problema da reprodução ampliada não é problema da circulação da mais-valia, pois a mais-valia circula com o valor das mercadorias. O problema é, pois, de resolver como pode circular uma massa de valor continuamente crescente. Evidentemente, a solução tomba sobre a análise já realizada por Marx quanto à determinação da quantidade de dinheiro para circular as mercadorias, análise essa apresentada na seção $2 b$ sobre $O$ curso do dinheiro, no terceiro capítulo do primeiro volume d'O Capital. A isso se opõe Rosa, dizendo que não se pode voltar à análise da circulação simples de mercadorias quando o problema se trata da reprodução ampliada do capital. A solução para a reprodução simples não é, segundo ela, uma solução para a o problema da realização na reprodução ampliada (Luxemburgo, 1976, p. 145).

No entanto, a chave da reprodução ampliada está na reprodução simples que ela despreza como uma ficção ou, no melhor dos casos, como a raiz quadrada de menos um $(-1)$.

Tomemos o exemplo da reprodução simples, na qual a necessidade de capital constante de reposição no departamento II é igual, em valor, às necessidades de meios de consumo por parte dos capitalistas e trabalhadores do departamento I: 


$\begin{array}{lll}c & v & m \\ 4000 & 1000 & 1000 \\ 2000 & 500 & 500\end{array}$

O dispêndio do fundo de consumo dos capitalistas do departamento I permite aos capitalistas do departamento II a compra da segunda metade dos meios de produção consumidos no ano anterior. Essa compra que para o departamento II é uma reposição do capital consumido, para o departamento I é precisamente a venda do seu produto excedente. Ou seja, o dinheiro lançado à circulação pelos capitalistas do departamento I reflui realizando a sua própria mais-valia. No caso da reprodução simples, ela aceita que o dinheiro passe de mão em mão entre capitalistas. A circulação do dinheiro entre eles permite que o produto destinado ao seu consumo seja absorvido, restando o dinheiro em suas próprias mãos. Mas a realização da mais-valia na reprodução ampliada não pode advir dos capitalistas, pois isso significaria que os eles já teriam em sua posse o equivalente ao aumento do valor. E tampouco pode advir dos trabalhadores. Ao vender aos trabalhadores, os capitalistas apenas recuperam o capital variável com o que a classe trabalhadora não pode realizar nem um átomo da mais-valia. Para quem eles produzem a parte destinada à acumulação? De onde vem a demanda que absorve a expansão crescente da produção? Quem há de comprar a parte do produto excedente que sobra após o consumo capitalista?

Rosa fala da dependência recíproca entre os departamentos I e II; que o departamento II depende da produção de $\Delta c_{\text {II }}$ no departamento I e que o departamento I depende da produção de $\Delta v_{1}$ no departamento II. Mas, em sua opinião, essas são condições para que a acumulação se dê; não garantem que ela se dará. Para que a acumulação se efetue de fato é preciso que exista uma perspectiva de aumento da demanda. Existem duas demandas aqui: a demanda imediata e a demanda pelo produto futuro que advirá com a expansão do capital produtivo.

Tomemos primeiro a demanda imediata. Nosso $\Delta c_{\text {II }}$ representa demanda para aquela parte do sobre-produto do departamento I que excede as necessidades internas daquele departamento. Essa demanda advém do departamento II; $\Delta v_{\text {I }}$ é o aumento da demanda que advém do departamento I e que realizará aquela parte do excedente de II que resta após suprir meios de consumo equivalentes a $v_{\mathrm{I}}+v_{\mathrm{II}}+\Delta v_{\mathrm{II}}$. Ora, se o sistema é capaz de escoar 
o excedente no tempo zero, por que ele não será capaz de escoar o excedente no tempo 1?

Ao invés de pensar assim ela diz: quem precisa de meios de produção adicionais? O departamento II? Para quê? Para produzir meios de consumo adicionais. Quem precisa de meios de consumo adicionais? $O$ departamento I. Giramos em círculo, ela conclui. Mas não é esse precisamente o círculo da acumulação? E quem ela tem em mente nesse momento? Será a ciranda de expansão de Tugan-Baranowsky que ela procura ridicularizar?

Uma vez gastos os salários e reposto o capital consumido, o sobre-produto cujo valor representa a mais-valia a ser realizada em dinheiro deve ser comprada pelos próprios capitalistas. Porém, raciocina ela, se a classe capitalista já possui o dinheiro para realizar a mais-valia, então não haveria expansão do valor do capital e a produção capitalista não faria sentido. Itoh sugere que Rosa teria errado ao considerar o circuito do capital dinheiro na análise da realização do sobre-produto. Visto pela ótica do circuito do capital dinheiro, parece pouco plausível a realização de todo o sobre-produto quando todos os capitalistas aparecem como vendedores ao mesmo tempo! Isso sugeria que nos esquemas de reprodução de Marx a classe capitalista deveria ter em sua posse todo o dinheiro para realizar o sobre-produto. Nessas condições, a realização da mais-valia seria apenas uma troca de mãos do dinheiro previamente existente, fato que lhe parecia ser absurdo. No entanto, na reprodução simples funciona dessa forma, já que o dinheiro reservado para o consumo capitalista é jogado na circulação e realiza o produto excedente que existe na forma de meios de consumo dos capitalistas. Mas, mesmo na reprodução simples não é necessária uma quantia de dinheiro equivalente ao valor do sobre-produto. Basta que o dinheiro existente realize várias operações em sequência. Uma mesma peça monetária serve para a realização de um múltiplo de valor de mercadorias vendidas. $\bigcirc$ mesmo ocorre na reprodução ampliada com a diferença de que com o aumento contínuo do produto excedente é preciso que a eficiência de circulação do dinheiro aumente ou que aumente a própria quantidade de dinheiro em circulação por meio da mobilização de dinheiro na forma de tesouros pela circulação ativa. A eficiência de circulação do dinheiro pode aumentar, seja com o aumento da velocidade de circulação do dinheiro, seja com o desenvolvimento de sua função como meio de pagamento. É assim que Marx apresenta o problema no capítulo XVII sobre A circulação da Mais-valia (1985c, p. 254). 


\section{A multiplicação de interpretações}

\subsection{Bauer}

A resposta de Bauer, encarregado por Kautsky de escrever uma revisão crítica do livro de Rosa Luxemburgo para a Die Neue Zeit, marca o início de uma guinada no debate sobre a natureza das crises econômicas capitalistas.

Bauer sugere, corretamente, que a concepção de Rosa implicava que fosse preciso primeiro vender o sobre-produto correspondente à parte não consumida da mais-valia e só depois, de posse do dinheiro, realizar a acumulação. E mesmo essa última dependia de expectativas de venda do produto futuro. Sobre isso, Bauer diz que "é igualmente impossível realizar a parte destinada à acumulação, primeiro, e somente depois comprar os elementos materiais do capital produtivo: a realização da acumulação ocorre exatamente na venda do segundo componente do sobre-produto" que na notação dele é $\mathrm{k}+\mathrm{B}$, respectivamente a parte da mais-valia destinada ao aumento do capital constante e a parte da mais-valia destinada ao aumento do capital variável (Bauer, 1986, p. 102-103). Ele tem razão! Por outro lado, a hipótese de venda do sobre-produto no exterior implicaria a necessidade de compra dos elementos do capital adicional também no exterior. Mas onde? Se o mercado exterior deve ser não capitalista, como encontrar ali os elementos avançados do capital constante? Bauer insiste que o problema é que Rosa concebe a compra dos elementos adicionais do capital produtivo somente no segundo ano, necessitando essa operação, portanto, de uma venda prévia. Bauer conclui que a venda do sobre-produto correspondente a $\Delta c$ e $\Delta v$ no exterior, ao invés de tornar a acumulação possível, a inviabilizaria por completo.

Bauer mostra que o processo de acumulação é ao mesmo tempo o processo de realização do produto e que, contrariamente ao que preconizava Luxemburgo, a exportação dos produtos correspondentes a $\Delta c_{\mathrm{I}}$ e $\Delta c_{\mathrm{II}}$, significaria um impedimento à continuidade da acumulação. Isso faz sentido, pois, se no momento seguinte é preciso ter uma fonte de demanda externa, então se supõe que no momento seguinte o sobre-produto encontre compradores externos. Nesse caso, a acumulação só poderia prosseguir se a realização do excedente no exterior correspondesse uma compra de meios de produção e meios de consumo no exterior. 
Para mostrar que o capitalismo cria seu próprio mercado interno, Bauer não faz mais do que propor de novo os esquemas de reprodução com as características assim modificadas em relação aos esquemas propostos por Marx: o capital constante cresce a $10 \%$ ao ano enquanto o capital variável cresce a $5 \%$ ao ano; o crescimento populacional é também de $5 \%$ ao ano, enquanto a taxa de mais-valia permanece constante em $100 \%$. Esses parâmetros implicam que a composição orgânica do capital cresce continuamente ao longo do tempo, ainda que o período de tempo do seu experimento seja relativamente curto: quatro anos.

Os seus esquemas mostram o que Marx havia mostrado antes: a demanda é formada no interior do processo de acumulação de capital, e se houvesse um equilíbrio permanente entre acumulação e população a reprodução poderia se perpetuar sem problemas de demanda.

No entanto, no capitalismo não há uma coordenação prévia entre acumulação e crescimento populacional. Assim, ele passa a descrever as crises cíclicas do capitalismo ocasionadas por descompassos entre a taxa de crescimento do capital variável, $g_{v}$, e a taxa de crescimento populacional, $g_{p}$. O crescimento caracterizado por $g_{v}<g_{p}$, ele denomina de sub-acumulação e o crescimento caracterizado por uma relação $g_{v}>g_{p}$, ele denomina de sobreacumulação. Quando a acumulação não é capaz de absorver o crescimento da força de trabalho $\left(g_{v}<g_{p}\right)$, o exército industrial de reserva cresce e os salários diminuem. Ao mesmo tempo ele diz que o mesmo processo que cria desemprego reduz o valor da força de trabalho, referindo-se aqui ao efeito do aumento da produtividade do trabalho através do emprego de máquinas e instrumentos poupadores de mão-de-obra. A queda dos salários se efetua no mercado de trabalho por meio da concorrência entre os trabalhadores. Ou seja, a redução dos salários para o nível do valor da força de trabalho é realizada pelo efeito negativo do maior desemprego sobre os salários. ${ }^{12}$ Com a diminuição dos salários, a massa de mais-valia aumenta. Com a mesma taxa capitalista de acumulação definida como proporção da mais-valia transformada em capital adicional,

$$
a_{c}=\frac{\Delta c+\Delta v}{m}
$$

12 No entanto, a diminuição dos salários devido a uma acumulação menor do que o ritmo de crescimento da população não é necessariamente causada pelo aumento da composição orgânica do capital. Pode muito bem sê-lo pela simples lentidão do crescimento. 
a taxa de crescimento do capital variável aumenta à medida que aumenta a massa de mais-valia, até que se equipare à taxa de crescimento populacional, ou seja, até que $g_{v}=g_{p}$.

"Eventualmente a crescente taxa social de acumulação alcança um ponto no qual o capital variável cresce mais do que a população" (Bauer, 1986, p. 105). Essa é a situação de sobreacumulação e aqui Bauer cita o capítulo sobre as "Contradições Internas da Lei", de Marx, e descreve a devastadora crise que se segue até que se restabeleça o equacionamento equilibrado entre crescimento do capital variável e força de trabalho disponível.

Assim, sua teoria se reduz ao ajuste da acumulação à taxa de crescimento populacional. A alternância periódica entre prosperidade, crise e depressão é apenas o modo pelo qual o processo de ajuste da acumulação capitalista ao crescimento populacional se manifesta. Contrariamente a Rosa, o limite da acumulação está na força de trabalho disponível e não nos mercados não capitalistas, ainda que segundo ele os mercados externos sirvam para flexibilizar os limites impostos pelo crescimento populacional. Assim, tendo tomado o capítulo da "Lei Geral da Acumulação Capitalista" como inspiração teórica, Bauer sugere que o imperialismo é uma forma de romper as amarras do crescimento populacional quando a composição orgânica do capital é constante. $O$ imperialismo não é para ele um meio de realizar a acumulação, mas sim um meio de expandir os seus limites (Bauer, 1986, p. 109) e facilitar a superação das crises de sobreacumulação.

Bauer produz o primeiro esquema de variação cíclica dos salários, tal como o resultado apresentado por Marx na primeira seção do capítulo XXIII, mas curiosamente como resultado de um processo de acumulação com aumento constante da composição orgânica. Uma vez que o ritmo de acumulação ultrapasse o ritmo de oferta de força de trabalho, a acumulação produz uma alta de salários que leva à situação de sobreacumulação descrita por Marx. Essa circunstância dá origem a uma crise aguda, mas cuja duração é determinada pelo tempo de ajuste da acumulação de capital ao crescimento populacional. No entanto, não deixa de chamar a atenção o fato de que se possa considerar a possibilidade de crises recorrentes ocasionadas pela escassez de força de trabalho num esquema no qual a composição orgânica do capital cresce continuamente. 


\subsection{Grossmann}

Grossmann se opõe a Hilferding, Tugan-Baranowsky e também a Bauer. De acordo com o esquema de Bauer, o capitalismo não terminaria devido a um limite objetivo, mas somente através da educação política dos trabalhadores, isto é, somente através da intervenção subjetiva da classe trabalhadora. Contrariamente a essa visão, Grossmann defende a ideia de que se o capitalismo pode se desenvolver sem obstáculos, então o elemento subjetivo não tem um suporte objetivo para realizar o socialismo.

Diz ele que os resultados obtidos por Bauer são devidos ao curto período de tempo utilizado pelo seu autor. Por isso ele se propõe a expandir o exemplo de Bauer com o intuito de mostrar que, a partir de certo ponto, a acumulação não poderá crescer suficientemente rápido para absorver o crescimento populacional da força de trabalho, já que o montante da mais-valia absorvido pelo capital constante é tal que não há mais-valia suficiente para absorver a força de trabalho disponível. Ele argumenta que enquanto o capital é capaz de crescer no mesmo ritmo da força de trabalho, a acumulação capitalista cria seu próprio mercado (Grossmann, 1992, p. 70). Depois de certo ponto a mais-valia não é capaz de sustentar o equilíbrio $g_{v}=g_{p}$, do que adviria a formação de um exército industrial de reserva (Grossmann, 1992, p. 78): no ano 1, a acumulação em capital constante representa $20 \%$ da mais-valia; no ano 35, ela representa $97 \%$ da mais-valia e não há mais-valia suficiente para prover o aumento de $5 \%$ da força de trabalho.

O sistema entra em colapso, fato que contradiz a regeneração cíclica preconizada por Bauer. $O$ colapso é consequência das próprias premissas de Bauer, que Grossmann conserva e reproduz nos seus esquemas. Sob essas premissas, o consumo capitalista tem que progressivamente dar lugar às necessidades de aumento do capital, de modo que a proporção da mais-valia consumida pelos capitalistas cai de $70,9 \%$ no quinto ano para $0,45 \%$ no $34^{\circ}$ ano, sendo que a partir do ano 21 a massa de mais-valia consumida pelos capitalistas começa a se reduzir em termos absolutos.

Assim se atingiria uma situação na qual, no $35^{\circ}$ ano, os capitalistas não disporiam de mais-valia para o seu consumo. É a partir desse ano que a acumulação capitalista perderia sentido para os capitalistas! Isso mostra que o consumo capitalista "é uma condição essencial da acumulação de capital" e para a própria existência do capitalismo (Grossmann, 1992, p. 81). Esse ano marcaria, no esquema de Grossmann, o momento do colapso durante 
o qual se sucederia uma série de crises econômicas. Desse modo, conclui Grossmann, a crítica de Bauer a Rosa é infundada: o sistema não pode se desenvolver continuamente sem topar com os seus limites absolutos.

Ele admite que muito antes do ano $35^{\circ}$ ano o capital lutaria para reverter a tendência ao declínio do fundo de consumo capitalista, por exemplo, abandonando a taxa de expansão de $10 \%$ do capital constante. Nesse caso, a acumulação não mais seria capaz de andar ao ritmo do crescimento populacional e um exército industrial de reserva crescente se formaria mesmo com salários constantes. Ou seja, a redução da acumulação não seria ditada pelos salários mais altos como propunha Bauer (Grossmann, 1992, p. 82).

O fundamental é que Grossmann pensa ter derivado uma tendência à sobreacumulação independente do aumento dos salários e, portanto, ele faz uma leitura do capítulo XV viezada para a sobreacumulação não pela redução da taxa de mais-valia, mas pelo efeito do aumento da composição orgânica sobre a taxa de lucro. Mas, curiosamente, ele não diz nada sobre a sua opção de leitura daquela parte d'O Capital que trata explicitamente da sobreacumulação causada pelo aumento dos salários. Grossmann cita Marx precisamente onde este último se refere à sobreacumulação causada pela diminuição da taxa de mais-valia, sendo que no seu esquema a sobreacumulação resulta da composição orgânica crescente com taxa de mais-valia constante!

A teoria do colapso de Grossmann é ao mesmo tempo uma teoria das crises, já que a tendência ao colapso põe em moto processos que reduzem a sobreacumulação "à magnitude compatível com a normal valorização". A recorrência das crises nada mais é do que a fenomenologia do colapso: "A teoria do colapso de Marx é a base necessária de sua teoria das crises", pois, de acordo com Marx, "as crises são apenas a forma na qual a tendência ao colapso é interrompida" (Grossmann, 1992, p. 85). Mas o mecanismo como um todo apenas aproxima o capitalismo de sua crise final à medida que as contratendências vão perdendo a eficácia.

Por fim, ele enfatiza que o colapso não pode ser derivado a partir da queda da taxa de lucro, mas sim a partir da queda da massa de lucro: não se poderia explicar como no ano 34 , com uma taxa de lucro de $9,7 \%$, o sistema sobrevive e, no entanto, no ano seguinte, com uma taxa de 9,3\% o sistema entra em colapso (Grossmann, 1992, p. 103). A diminuição da taxa de lucro somente revela a diminuição relativa da massa de lucro relativamente ao capital investido. 
Para Grossmann, e para aqueles que seguiram suas proposições gerais, é o aumento da composição orgânica do capital a causa da diminuição da taxa de lucro, enquanto para aqueles que seguiram as pegadas de Bauer a sobreacumulação resulta de um aumento de salários e da consequente redução da taxa de mais-valia, $m^{\prime}$.

\section{Confrontos atuais}

Assim se abre a dicotomia das teorias de crise de superacumulação entre aquelas causadas pelo aumento dos salários e aquelas causadas pelo aumento da composição orgânica do capital, $q_{0}$. Nas duas, a redução da taxa de lucro termina por causar uma estagnação na massa de lucro, fenômeno que inicia um processo de destruição de capital. Como a taxa de mais-valia $\left(m^{\prime}\right)$ e a composição orgânica do capital $\left(q_{0}\right)$ são os dois componentes da taxa de lucro, as escolas de crise de sobreacumulação podem ser vistas diretamente na fórmula da taxa de lucro:

$$
\ell^{\prime}=\frac{m^{\prime}}{1+q_{0}}
$$

Itoh (1988, p. 294) apresenta a lei de tendência de queda da taxa de lucro como um fenômeno independente de variações na taxa de mais-valia, mostrando que a razão $q=(v+s) / c$ cai continuamente ao longo do tempo e que, portanto, $p^{\prime}=s /(c+v)$ deve tender a cair já que o seu limite máximo $q$ é declinante. Essa é a apresentação standard da tendência de queda independente da taxa de mais-valia e também assim apresentada por Shaikh (1978). No entanto, Itoh apresenta algumas ponderações para mostrar que a tendência de queda da taxa de lucro não é capaz de produzir uma teoria da crise. Por isso, ele opta pela teoria da sobreacumulação causada pela exaustão da força de trabalho disponível. O aumento dos salários iniciaria um conjunto de distorções de preços (Itoh, 1988, p. 309) que incentivaria a especulação com base no crédito e nas reservas de capital dinheiro latente. Com isso, a renovação dos fundos de dinheiro ocioso que forma a base do crédito comercial se vê prejudicada. $\bigcirc$ crédito comercial começa a sofrer os percalços da redução da liquidez fazendo com que as notas circulem por períodos mais curtos. A independência do crédito entre capitalistas relati- 
vamente ao crédito bancário desaparece, aumentando a demanda por desconto de letras de câmbio. Tudo isso acaba causando um aumento da taxa de juros (Itoh, 1988, p. 311). A crise começa a partir do colapso de alguns empreendimentos especulativos, principalmente no ramo do comércio por atacado (Itoh, 1988, p. 313).

O curioso é que Itoh não se interessou pela possibilidade de que a superacumulação sobreviesse após a estagnação da massa de lucros eventualmente ocasionada pela diminuição contínua de $q=(v+s) / c$. Essa possibilidade foi explorada por Shaikh (1991, p. 349-350) num modelo simples para explicar a sobreacumulação com base no aumento da composição do capital. De fato ele apresenta Grossmann como o primeiro grande marxista a direcionar a discussão para além do subconsumismo e da desproporcionalidade. Shaikh recupera essa análise observando que na teoria de Grossmann a diminuição da taxa de lucro leva eventualmente à estagnação da massa de lucro. Há um valor crítico para a taxa de lucro no qual a massa de lucro não pode ser compensada pelo aumento do estoque de capital. Nesse momento se produz a crise de sobreacumulação, pois o capital adicional $\Delta C$ não produz lucro algum, fato que desencadeia as mesmas consequências descritas anteriormente.

Itoh não considerou essa possibilidade, provavelmente porque a sobreacumulação com base no aumento dos salários oferecia, com as distorções setoriais que ela causava, uma articulação com a análise efetuada por Marx no contexto do funcionamento do sistema de crédito, aspecto que provavelmente para Itoh enriquecia sobremaneira a análise da crise.

Para Dobb é o aumento dos salários que leva à mecanização. Ele não vê a mecanização como movimento autônomo causado pela necessidade capitalista de controle sobre o processo de trabalho. Portanto, para ele, o aumento da composição orgânica do capital, através da substituição da força de trabalho por máquinas, é uma tentativa dos capitalistas recuperarem a lucratividade. Basicamente, o processo se passaria assim: perto do pico da atividade econômica há uma relativa exaustão do exército industrial de reserva e os salários começam a aumentar fazendo com que os capitalistas tendam a adotar métodos de produção do tipo labor-saving (Dobb, 1945, p. 113-114). Quando o aumento dos salários faz com que o aumento do estoque de capital não produza um aumento da massa de lucros, o sistema entra em regime de sobreacumulação e a crise faz com que se forme novamente uma reserva de trabalho disponível a salários mais baixos, o que por 
sua vez diminui o ímpeto de adoção de técnicas de mais alta composição orgânica do capital, já que os métodos menos eficientes se tornarão novamente lucrativos (Dobb, 1945, p. 122).

A diferença entre Dobb e os outros partidários modernos do profit squeeze é a causa do aumento dos salários: para Dobb, esse aumento advém da contração do exército industrial de reserva que resulta da fase de expansão econômica, enquanto que para os partidários da linha alternativa do profit squeeze, o aumento dos salários é produto da força sindical dos trabalhadores. Mas esta já é outra história a ser elaborada em trabalho subsequente.

\section{Observações finais}

Como sabemos, na parte V do terceiro volume d'O Capital, Marx enfatizou o caráter cíclico das crises capitalistas, crises que forneceriam as condições para a retomada da acumulação.

Entre essas condições figuram a acumulação do capital monetário que ocorreria na fase letárgica de recuperação. Essa acumulação monetária reduziria a taxa de juros, a qual permaneceria ao redor do seu nível médio durante toda a fase de recuperação devido à proeminência do crédito direto de mercadorias entre capitalistas durante essa fase. A recuperação econômica elevaria a taxa de lucro que, juntamente com a manutenção de uma taxa de juros baixa, conduziria a uma taxa de lucro de empresário crescente.

O aumento da taxa de lucro de empresário levaria, durante a fase de aceleração do ciclo, a um aumento da demanda de crédito, uma vez que os capitais mais alavancados obtêm taxas de lucro sobre o capital próprio maiores que a média, como demonstrado por Hilferding (1985, p. 93).

Ocorre que o balanço da reprodução, como exposto nos dois capítulos finais do segundo volume d'O Capital, requer um peso compensatório entre capitais formadores de fundos e capitais em fase de ativação produtiva dos seus fundos previamente acumulados. Ora, a fase de aceleração rompe esse balanço compensatório, uma vez que o espectro de capitais se desloca para o polo daqueles que estão em fase de acumulação produtiva, nos quais se incluem os capitais que antecipam seus fundos por meio do crédito, desequilíbrio que conduz a um processo inflacionário e à consequente demanda de crédito para fins especulativos. Quando a fase especulativa 
entra em colapso, ela faz aparecer uma miríade de empresas endividadas que têm que liquidar parte dos seus ativos, com o que o capital sofre uma desvalorização que marca, junto com a desvalorização do preço da força de trabalho, as condições para a formação de um novo ciclo.

Como se vê, a teoria de Marx sobre a crise requer a convergência de três elementos fundamentais de análise: a concorrência presente no conceito de taxa de lucro do empresário sobre o capital próprio; a análise da reprodução do capital agregado e, por fim, a função do crédito no processo de acumulação. No entanto, como vimos, as teorias marxistas clássicas se fixaram em aspectos parciais da teoria apresentada n'O Capital.

Em parte isso se deve ao fato de que os dois grandes epicentros do debate sobre a crise tenham se consolidado antes da publicação do terceiro volume d'O Capital, volume no qual as condições concretas para a teoria da crise, o crédito e a concorrência, foram expostos. Como vimos, esses dois epicentros foram, por um lado, a Rússia Czarista onde Bulgakov, Tugan-Baranowsky, Struve e Lênin se confrontaram com os marxistas populistas conhecidos como narodnikis e, por outro, a Alemanha, onde reformistas e revolucionários se confrontaram no interior do SPD, o Partido Social Democrata Alemão, confronto esse que contou com a participação importante de figuras proeminentes do Partido Social Democrata Austríaco.

No pós-guerra, novos deslocamentos se produziram: o subconsumismo ganhou novas raízes nos Estados Unidos enquanto o profit-squeeze, a teoria do aumento dos salários como causa da crise, ganhou adeptos na Inglaterra, Japão e no próprio EUA.

A cronologia das obras principais, apresentada abaixo com o propósito de guiar o leitor interessado no tema, reproduz no tempo a genealogia apresentada na Figura 1.

1892 Kautsky: Luta de Classes

1993 Lênin: Sobre os mercados

1894 Tugan: Industrial Crisis in England ${ }^{13}$

1897 Bulgakov: Os mercados na produção capitalista

1899 Lênin: O desenvolvimento do capitalismo na Rússia

13 Lênin (1974, p. 36) cita essa obra como Las crisis industriales, simplesmente. Hilferding (1985, p. 420) faz referência ao título em alemão: Theorie und Geschichte der Handelskrisen in England. Luxemburgo também cita a obra em alemão, mas como Studien zur Theorie und Geschichte der Handelskrisen in England (Luxemburgo, 1976, 283). 
1901 Kautsky: Krisentheorien

1910 Hilferding: O capital financeiro

1911 Kautsky: Finance capital and crisis

1913 Luxembourg: A acumulação de capital

1913 Bauer: Acumulação de capital

1939 Grossman: The law of accumulation

A genealogia que se pretendeu iniciar neste artigo não é exaustiva. Aqui procuramos tão somente traçar as linhas mais salientes da história das teorias de crise, localizando sua origem na obra de Marx e dando especial atenção em apresentar mais detalhadamente algumas das teorias menos estudadas.

\section{Referências}

BAUER, O. The accumulation of capital. History of Political Economy, 18:1, pgs. 87-110, 1986.

BODDY, R.; Crotty, J. Class conflict, keynesian policies and the business cycle. Monthly Review, volume 26:5, p. 1-17, 1974.

DOBB, M. Political Economy and Capitalism. Some Essays in EconomicTradition. New York: International Publishers, 1945.

GIUSSANI, P. Reproduction Schema, in Bottomore, T. (ed.) A Dictionary of Marxist Thought. Cambridge, MA: Harvard University Press, 1983. p.420-422.

GROSSMANN, H. The Law of Accumulation and Breakdown of the Capitalist System, Being also a Theory of Crises. London: Pluto Press, 1992.

HILFERDING, R. Finance Capital. A Study of the Latest Phase of Capitalist Development. London: Routledge \& Kegan Paul, 1985.

HOWARD, M. C.; KING, J. E.. A History of Marxian economics. vol. I, 1883-1929. New Jersey: Princeton University Press, 1989.

ITOH, M. Value and Crisis. Essays on Marxian Economics in Japan. New York: Monthly Review Press, 1980.

ITOH, M. The Basic Theory of Capitalism. Totowa, New Jersey: Barnes \& Noble Books, 1988

LÊNIN, V. I. El Desarrollo del Capitalismo en Rusia. Barcelona: Editorial Ariel, 1974.

LUXEMBURGO, R. L'Accumulation du Capital. Paris: François Maspero, 1976.

MARX, K. Theories of Surplus Value. part. II. Moscow: Progress Publishers, 1968.

MARX, K. Grundrisse. Foundations of the Critique of Political Economy. London: Penguin Books, 1973.

MARX, K. O Capital. Crítica da Economia Política. vol. I. São Paulo: Nova Cultural, 1985a.

MARX, K. O Capital. Crítica da Economia Política. vol. II. São Paulo: Nova Cultural, 1985 b. 
MARX, K. O Capital. Crítica da Economia Política. vol. III. São Paulo: Nova Cultural, 1985c.

MARX, K. O Capital. Crítica da Economia Política. vol. IV. São Paulo: Nova Cultural, 1988.

MARS, K. O Capital. Crítica da Economia Política. vol. V. São Paulo: Nova Cultural, 1986.

SHAIKH, A. Valor, Acumulación y Crisis. Ensayos de Economia Política. Bogotá: Tercer Mundo Editores, 1991.

SHAIKH, A. An introduction to the history of crisis theories. U.S. capitalism in Crisis. The Union for Radical Political Economics. New York: Union for Radical Political Economics,1978. p. 219-240.

SWEEZY, P. M. Teoria do Desenvolvimento Capitalista. Rio de Janeiro: Zahar Editores, 1973.

\section{Sobre o autor}

FranciscoPauloCipolla - cipolla@ufpr.br

Universidade Federal do Paraná.

\section{Sobre 0 artigo}

Recebido em 13 de junho de 2016. Aprovado em 18 de setembro de 2016. 